\title{
INFLUENCE OF GENDER-BASED VIOLENCE ON ABSOLUTE POVERTY AMONG WOMEN IN MADOGO WARD, TANA RIVER COUNTY, KENYA
}

\author{
Kevin Nderitu Kaguthi ${ }^{1 i}$, \\ Kennedy Mutundu ${ }^{2}$ \\ ${ }^{1}$ Postgraduate Student, \\ Department of Social and Development Studies, \\ Mount Kenya University, \\ Kenya \\ 2Professor, \\ Department of Social and Development Studies, \\ Mount Kenya University, \\ Kenya
}

\begin{abstract}
:
Gender inequality oppresses development among women and girls and is worsened by absolute poverty among women in Kenya. Poverty denies people choices and opportunities to participate in economic, political, and social activities while gender inequality denies women and girls equal opportunities as men and boys. Despite numerous interventions by the government through policies and laws gender inequality is on the rise and a great hindrance to development. Many women-headed households are not able to meet their basic needs due to inadequate income, lack of education, gender-based violence, and inaccessibility of primary health care. The objectives of this research were to analyze the influence of gender-based violence on absolute poverty among women in Madogo Ward, Tana River County. A descriptive research design and a quantitative research approach were used for the investigation to assemble the necessary quantitative information in Madogo Ward. The units of observation for this study were women who live in the Madogo Ward. The research has found out that there is a high level of absolute poverty among women with $86 \%$ of respondents living below the absolute poverty line. The results also indicated that there is a high likelihood of women to face gender-based violence in the village and at home. The research found out that many women access medical facilities but lack of medication and being unable to afford private health care leaves women without primary health care when needed. This research recommends that the government works towards addressing the high levels of gender-based violence by developing community-based protection mechanism for
\end{abstract}

i Correspondence: email kevnderi@gmail.com 
women and girls and provision of primary healthcare for women in Madogo Ward which would reduce the high levels of absolute poverty.

Keywords: absolute poverty, gender-based violence

\section{Introduction}

Poverty and gender inequality have become a big obstacle to development in Africa mostly endured by women. Gender inequality is a violation of human rights against women while poverty denies women a choice and opportunity to participate in economic, social, and political development (UNDP, 2018). Kenya is not an exception as women bear the biggest burden of poverty. 4.1 million women in Kenya live below the $\$ 1.90$ absolute poverty line (World Data Lab, 2020). Women in Africa continue to grapple with issues of gender inequality that have predisposed them to illiteracy, gender-based violence, and poor health. According to the World Bank (2015), 10 percent of the humans lived in absolute poverty with women taking a larger portion.

COVID19 which is a global pandemic in 2020 has exposed the vulnerabilities of the low-income earners and vulnerable groups such as women. Kenya has imposed partial lockdown and curfew that has led to massive job losses for Kenyans working in blue-collar and semi-skilled jobs living in urban informal settlements and rural areas and as such predisposed them to poverty. Women who mostly work in informal jobs such as laundry and domestic work have been laid off. Even if the whole population has not been infected with COVID19 the impacts are felt by every citizen (Austrian et al., 2020).

Health as a key component in eradicating poverty is agenda one in the SDGs. The health of a population is a key aspect in economic development as healthy nations lead to a working nation thus improving the economic status of the country. Women face a variety of health issues that affects men less such as reproductive health. For a population to operate optimally the health of the population has to be good. The SDGs have been ratified by governments all over the world thus showing commitment to improving the health of the population and eradicating poverty in its midst including among women (Riumallo-Herl et al., 2018).

Tana River County in Kenya is considered one of the poorest counties. 76.9 percent of adults considered to be in the labor workforce living in the county are unemployed. 70 percent of people living in Tana River County are considered to be living below the absolute poverty line according to the CIDP 2018 - 2022 with a majority being women. The literacy levels among adults living in the county are 35.8 percent showing a great majority being semi-illiterate and illiterate. Gender-based violence in the county is high with domestic violence, FGM, child marriage, and sexual violence being erratic. Women are also facing challenges in accessing sexual and reproductive health supplies such as family planning contraceptives and treatment with many women delivering children at home and putting them at a higher risk of health complications and even death. All the challenges are evident to weigh down on women's participation of women living below 
the absolute poverty line in development. Women are not able to access education, are victims of gender-based violence, and are not able to access appropriate primary health care leading to a high number of women in absolute poverty.

\section{Statement of the Problem}

Gender inequality denies girls and women an equal opportunity to participate in social, economic, and political activities as boys and men. Poverty among women is considered an undesirable situation that can be carried from one generation to the next if not addressed on time. Gender inequality and absolute poverty among women in Kenya and Tana River county lead women and girls to limited income opportunities, high illiteracy levels, child marriage, limited information and access to health facilities, and increased gender-based violence. Despite gender-related policies and interventions by devolved and central governments and civil society organizations increased gender inequality has become a barrier that has denied women and girls an equal opportunity as men and boys to access education, protection from violence primary health care, decision making, and adequate income to alleviate absolute poverty. Disparities between urban and rural settlements also to be manifested in development where rural areas tend to lag. 70 percent of people living in Tana River County are considered to be living below the absolute poverty line while over 65 percent of adults are illiterate. The pre-primary enrollment rate is at 65 percent while the secondary enrolment rate is at just over 20 percent. Tana River County currently has the least enrolment and transition rates in Kenya and on top of it the poorest performing in primary and secondary education as compared to other counties in 2019. Over 50\% of maternal deaths are associated with gender inequality factors such as female genital mutilations and child marriage which are also rife in Tana River County. This shows many children are not able to transit from primary to secondary education with girls taking a larger share of this in the county. Girls and women continue to languish in poverty due to underlying cultural baggage and gender norms that lead to underdevelopment. Gender roles assigned to women lead them into unpaid labor, the marriage of underage girls, gender-based violence such as FGM. Poor people in rural areas often go unsupported due to the multiple challenges faced with high illiteracy levels and below-par income generated. This research, therefore, seeks to establish the relationship between gender inequality and absolute poverty among women. This research will find out if access to education, gender-based violence, and access to primary health care among women and girls leads women to absolute poverty in Madogo Ward, Tana River County.

\section{Purpose of The Study}

The study's purpose is to explore the influence of gender-based violence on absolute poverty in Madogo Ward, Tana River County, Kenya. 


\subsection{Objectives of The Study}

The specific objective of this study was to analyse the influence of gender-based violence on absolute poverty among women in Madogo Ward, Tana River County.

\subsection{Research Questions}

The following questions will be answered in the research; Does access to gender-based violence have any influence on absolute poverty in Madogo Ward, Tana River County?

\section{Literature Review}

A study conducted in Kasarani Sub County in Kenya set out to investigate gender-based violence by school-going children. The study was conducted in eight public schools from Kasarani with a sample of 156 respondents. A multi-stage cluster sampling was conducted where the respondents were identified in different schools and classes and others due to their experience of gender-based violence. The study concluded that girls in schools experienced more gender-based violence compared to boys with physical, emotional, and sexual violence is most rampant (Barasa, Wamue-ngare, \& Wanjama, 2013).

Women in Kenya have been categorized as a vulnerable group together with the youth and children since the inequality in the country is in existence. Due to this, women have been allocated funds by the government through the women's enterprise fund to empower women. Women have utilized the funds and several women have started small and medium enterprises, paid for the education of children, and built homes for their families. The government has tried to address gender inequality through policies and programs to empower women (Misati \& Mwenzwa, 2018).

\subsection{Measurement of Poverty}

Understanding how gender inequality relates to absolute poverty it is important to adopt a measure of poverty that is accurate. The measurement of absolute poverty is important in monitoring the situation of persons deemed to be poor and inform policies to alleviate poverty (Loxha, 2016). The poverty measurement is important in advancing the knowledge of how absolute poverty relates to gender inequality in the household. Headcount index was coined by Foster (1984) and has been used to estimate the number of households living below the poverty line stipulated by the World Bank. The headcount index (HI) is a commonly used formula advanced to measure poverty at the household level. The HI measures the proportion of persons living below the poverty line proposed by the World Bank (Loxha, 2016). As a straightforward poverty index has been mostly used in academia. World Bank has developed a poverty line of $\$ 1.90$ and persons living below it are considered to be poor while those living above it are considered as non-poor. When people have incomes that are below $\$ 1.90$, they are considered not able to adequately meet the minimum basic requirements for living. In Kenya, 35.6\% of people 
are living below the poverty line which is the lowest in East Africa but higher when compared with other middle-income countries.

The formula for calculating $\mathrm{HI}$ is;

$$
H_{i}=\frac{1}{n} \sum_{i=1}^{n} I\left(y_{i}<z\right)
$$

where,

$\mathrm{H}_{\mathrm{i}}$ is the headcount index,

$\mathrm{n}$ is the total sample,

$\mathrm{y}_{\mathrm{i}}$ is the expenditure,

$\mathrm{z}$ is the poverty line.

The statistical formula for calculating the headcount index is simplified as;

$H_{i}=\frac{n_{p}}{n}$

where,

$\mathrm{H}_{\mathrm{i}}$ is the headcount index,

$\mathrm{n}_{\mathrm{p}}$ is the proportion of the sample that is poor,

$\mathrm{n}$ is the total sample size.

\subsection{Theoretical Literature}

\subsubsection{Structural-functionalist Theory}

According to Alhassan Rabiu (2018), the structural-functionalist theory describes women as being nurturing and caregivers since childbirth, and bringing up a child is naturally in their instincts and physique. This has led to women being allocated roles that are inclined more to work in the home taking care of children and other domestic chores. Men on the other hand are tasked with working to earn a living to feed the family and viewed as economically responsible for the family. Women are therefore left to work at home for unpaid and often hard work while men played an active role in economic activities and the end giving men more power and control in the family and seen as the head of the family (Rabiu, 2018). Women provide emotional and nurturing tasks while men head the family and provide leadership and materialistic needs.

A family is viewed in society as being complete once it has a father, mother, and children with all allocated tasks that conform to their gender and acceptable in society. The culture, norms, and customs of the society places responsibilities and roles on both genders to ensure the smooth functioning and running of the system. Women are often allocated domestic-related roles while men are providers with bigger roles as leaders and breadwinners. These roles are all provided in regards to the biological constitution of either women or men (Alessio, 2016).

According to Alessio (2016), the roles mostly assigned to women in the home such as the domestic, nurturing, and reproducing roles often predispose women to poverty. 
Women are encouraged to get married and often socialized that way leading to child pregnancy and child marriage. Girls discontinue their schooling to take care of children and men at their own expense as they are not able to gain skillful knowledge to handle social and economic matters at home and in society. If the male figure leaves the family due to divorce or death the unskilled woman is left with the breadwinning duties and with little or no skills they end up in poverty (Ministry of Finance and UNICEF Ethiopia, 2019).

\section{Conceptual Framework}

Independent Variable

Dependent Variable

\section{Intervening Variable}

- Government policies on health, gender and education.

Gender based violence

- Child marriage

- Teen pregnancy

- Domestic violence
Absolute Poverty

- Food absolute poverty

- Non-food absolute poverty

Figure 1: Conceptual Framework

Figure 1 above highlights the conceptual framework of gender inequality (independent variable) and its relationship with absolute poverty (dependent variable). The indicators used for gender based violence are child marriage, teen pregnancy and domestic violence. The indicators of absolute poverty include the absolute food poverty line and the non-food absolute poverty line.

\section{Research Methodology}

The researcher used a quantitative research method to achieve the objectives of the research on the relationship between gender inequality and absolute poverty in Madogo Ward. The quantitative research method involved the collection of numeric data which the researcher analyzed using mathematical models of data analysis (Creswell \& Creswell, 2018). The researcher then ensured the alignment with statistical data collection methods. This study used a descriptive research design which can be defined as the collection of data and information to explain a theory (Rahi, 2017). The researcher used the descriptive research design to examine to which extent dependent and the 
independent variables are associated. This research targeted women living in Madogo Ward. Madogo Ward is in Bura Sub County which has a populace of 47,056 (KNBS, 2019). The population of Madodgo relies mostly on livestock rearing, small businesses, farming, and fishing along River Tana while others are pastoralists who go to look after animals where pasture is available. Another section of Madogo Ward population works as casual laborers in Garissa township and is active in building the vibrant town. The research reached out to women living in Madogo Ward and aged above 18 years old since they were old enough to provide consent for the research and were able to understand and articulate issues in the village.

Key informants living or working in the village or with persons that provide key services to the people of Ziwani were targeted. This includes officials from national and county government ministries mandated to provide services such as education, health, gender, statistics including vital statistics, labor, administration, and village officials.

This research utilized non-probability sampling techniques to obtain a sample of respondents that will represent the views of the whole population. This sampling procedure identified the sampling frame for the research, the sample size, and the sampling technique. The sampling frame included the total population in Madogo Ward which is 47,056 . Cochran's corrected formula of an infinite population for $50 \%$ proportion will be utilized to draw a sample size for this study (Kamau, John, et al., 2019).

The formula is applied below;

$$
\begin{gathered}
\mathrm{n}_{0}=\frac{\mathrm{z}^{2} \mathrm{pq}}{\mathrm{e}^{2}} \\
\mathrm{n}_{0}=\frac{(1.96)^{2}(0.5)(1-0.5)}{0.05^{2}}
\end{gathered}
$$

$\mathrm{n}_{0}=384.16=384$ respondents

To cater for non-response the sample size will be inflated by $10 \%$ that is;

$384+384(0.1)=384+38.4=422.4$

According to Cochran's calculations, the sample size will be 422 persons living in Madogo Location. Finally, simple random sampling was used to identify the specific respondents' households of the study. The respondents were be divided into clusters as per the locations in Madogo Ward. Thereafter, women living in the locations in Madogo ward were identified and formed the 422 respondents.

Primary data collection methods were applied during this research. Data collection methods and procedures employed during this research included structured questionnaires that were distributed to respondents through enumerators to derive the required information regarding the subject matter. Quantitative research tools are more focused on collecting data that can be counted and grouped for analysis. 


\section{Data Analysis, Interpretation and Discussions}

\subsection{Response Rate}

A response rate of 86.7 percent was achieved with a total of 366 respondents providing complete information out of 422 . The research study also sent out questionnaires to key informants that live, work or provide services in Madogo Ward. All the 6 key informants provided insight into the research study with specific topics relevant to the different departments. The researcher was able to get a high response rate from the key informants as the questionnaires were delivered on mail and followed up through phone calls and SMS.

\subsection{Research Findings on Objectives}

The researcher analysed the findings of gender-based violence among women and absolute poverty in Madogo Ward.

\subsection{Gender-based Violence and Absolute Poverty}

Table 1: Physical Violence and Absolute Poverty

\begin{tabular}{|c|c|c|c|}
\hline & & Level of & e poverty \\
\hline & & Poor & Non-poor \\
\hline Women 18-35 years from & Strongly Disagree & $9(2.9)$ & 0 \\
\hline this village are highly likely & Disagree & $9(2.9)$ & 0 \\
\hline to face physical violence & Neutral & $45(14.3)$ & $9(17.6)$ \\
\hline & Agree & $234(74.3)$ & $33(64.7)$ \\
\hline & Strongly Agree & $18(5.7)$ & $9(17.6)$ \\
\hline Total & & 315 & 51 \\
\hline
\end{tabular}

The research findings on Table 1 deduce that 5.8 percent of the respondents strongly disagreed (2.9 percent) and agreed ( 2.9 percent) while 14.3 percent gave a neutral view. On the other hand, 80 percent of the respondents either agreed (74.3 percent) or strongly agreed (5.7 percent) that women 18 to 35 years of age from the respective villages are highly likely to face physical violence.

Table 2: Sexual Abuse and Absolute Poverty

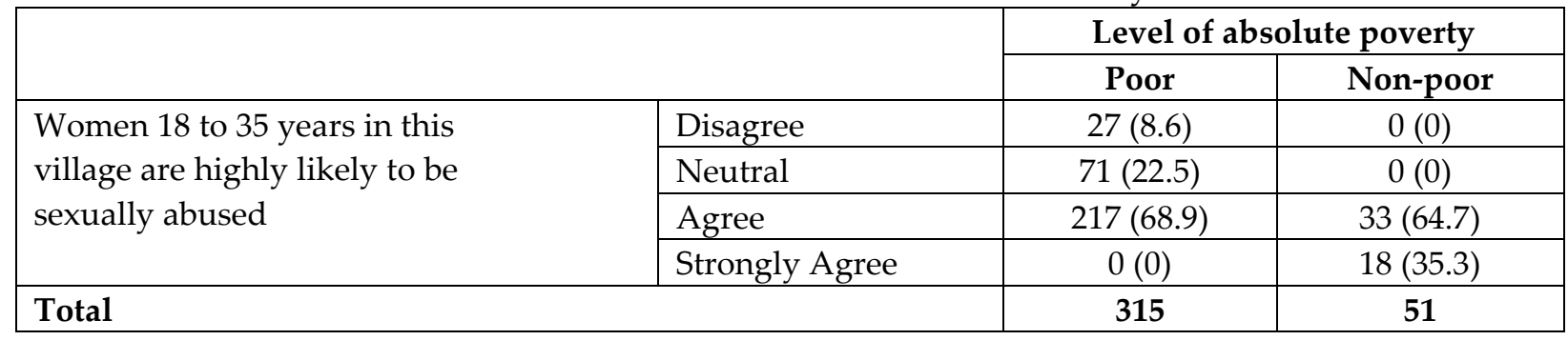

Table 2 shows the responses provided during the research with views sought from the respondents on the likelihood of women 18 to 35 years of age in the respective villages 
being sexually abused. The findings show that among the respondents living below the absolute poverty line 8.6 percent disagreed, 22.5 provided a neutral view and 68.9 percent agreed. Of the respondents living above the absolute poverty line 35.3 percent strongly agreed and 64.7 agreed that women 18 to 35 years of age in the respective villages were highly likely to be sexually abused.

Table 3: Girls 12-17 Years get Pregnant and Absolute Poverty Line

\begin{tabular}{|l|l|c|c|}
\hline \multicolumn{2}{|c|}{} & \multicolumn{2}{c|}{ Level of absolute poverty } \\
\cline { 3 - 4 } \multicolumn{2}{|c|}{} & Poor & Non-poor \\
\hline \multirow{2}{*}{$\begin{array}{l}\text { Girls 12 to 17 years in this } \\
\text { village are highly likely } \\
\text { to get pregnant }\end{array}$} & Strongly Disagree & $9(2.9)$ & $0(0)$ \\
\cline { 2 - 4 } & Neutral & $27(8.6)$ & $0(0)$ \\
\cline { 2 - 4 } & Agree & $253(80.3)$ & $42(82.4)$ \\
\cline { 2 - 4 } & Strongly Agree & $26(8.3)$ & $9(17.6)$ \\
\hline \multicolumn{2}{|l|}{ Total } & 315 & 51 \\
\hline
\end{tabular}

The research findings on Table 3 show that 2.9 percent of the respondents living below the absolute poverty line strongly disagreed, 8.6 percent were neutral on the subject, 80.3 percent agreed while 8.3 percent strongly agreed that girls between 12 and 17 years of age from the respective villages are highly likely to get pregnant. On the other hand, respondents living above the absolute poverty line 82.4 percent agreed and 17.6 percent strongly agreed that girls 12 to 17 years of age from the respective villages are highly likely to get pregnant.

Table 4: Girls 12 to 17 Blamed for Getting Pregnant and Absolute Poverty Line

\begin{tabular}{|c|c|c|c|}
\hline & \multicolumn{2}{|c|}{ Level of absolute poverty } \\
\hline & & Poor & Non-poor \\
\hline \multirow{4}{*}{$\begin{array}{l}\text { Girls } 12 \text { to } 17 \text { years of age } \\
\text { in this village are highly likely } \\
\text { to be blamed if they get pregnant }\end{array}$} & Strongly Disagree & $9(2.9)$ & $0(0)$ \\
\hline & Disagree & $9(2.9)$ & $9(17.6)$ \\
\hline & Agree & $279(88.6)$ & $42(82.4)$ \\
\hline & Strongly Agree & $18(5.7)$ & $0(0)$ \\
\hline \multicolumn{2}{|l|}{ Total } & 315 & 51 \\
\hline
\end{tabular}

The research findings on Table 4 show responses from respondents living below the absolute poverty line and those living above it on girls 12 to 17 years of age in the respective villages highly likely to be blamed if they get pregnant. Among respondents living below the absolute poverty line 2.9 percent strongly disagreed, 2.9 percent disagreed 88.6 percent agreed and 5.7 percent strongly agreed that girls aged between 12 and 17 years of age are highly likely to be blamed if they get pregnant. As for the respondents living above the absolute poverty line, 17.6 percent disagreed and 82.4 percent agreed that girls 12 to 17 years of age are highly likely to be blamed if they get pregnant. 
Table 5: Girls below 18 years Married and Absolute Poverty Line

\begin{tabular}{|l|l|c|c|}
\hline \multicolumn{2}{|c|}{} & \multicolumn{2}{c|}{ Level of absolute poverty } \\
\cline { 3 - 4 } \multicolumn{2}{|c|}{} & Poor & Non-poor \\
\hline \multirow{2}{*}{$\begin{array}{l}\text { Girls in this village are highly } \\
\text { likely to get married before } \\
\text { attaining 18 years }\end{array}$} & Neutral & $81(25.7)$ & 0 \\
\cline { 2 - 4 } & Agree & $225(71.4)$ & $42(82.4)$ \\
\cline { 2 - 4 } & Strongly Agree & $9(2.9)$ & $9(17.6)$ \\
\hline Total & $\mathbf{3 1 5}$ & $\mathbf{5 1}$ \\
\hline
\end{tabular}

Table 5 shows the responses to the research findings on girls in the respective villages being highly likely to get married before attaining 18 years among respondents living below and above the absolute poverty line of $\$ 1.90$. Among the respondents living below the absolute poverty line 25.7 percent were neutral, 71.4 percent agreed and 2.9 percent strongly agreed. Among the respondents living above the absolute poverty line, 82.4 percent agreed and 17.6 strongly agreed that girls in the respective villages are highly likely to get married before attaining 18 years of age.

\subsection{Cross-tabulation of Findings on Objectives}

The researcher analyzed the findings of gender-based violence among women and absolute poverty in Madogo Ward.

\subsubsection{Gender-based Violence and Absolute Poverty}

Table 6: Physical Violence and Absolute Poverty

\begin{tabular}{|c|c|c|c|}
\hline & & \multicolumn{2}{|c|}{ Level of absolute poverty } \\
\hline & & Poor & Non-poor \\
\hline \multirow{5}{*}{$\begin{array}{l}\text { Women } 18-35 \text { years from this } \\
\text { village are highly likely to face } \\
\text { physical violence }\end{array}$} & Strongly Disagree & $9(2.9)$ & 0 \\
\hline & Disagree & $9(2.9)$ & 0 \\
\hline & Neutral & $45(14.3)$ & $9(17.6)$ \\
\hline & Agree & $234(74.3)$ & $33(64.7)$ \\
\hline & Strongly Agree & $18(5.7)$ & $9(17.6)$ \\
\hline \multicolumn{2}{|l|}{ Total } & 315 & 51 \\
\hline
\end{tabular}

The research findings on Table 6 deduce that 5.8 percent of the respondents strongly disagreed (2.9 percent) and agreed (2.9 percent) while 14.3 percent gave a neutral view. On the other hand, 80 percent of the respondents either agreed (74.3 percent) or strongly agreed (5.7 percent) that women 18 to 35 years of age from the respective villages are highly likely to face physical violence.

Table 7: Sexual Abuse and Absolute poverty

\begin{tabular}{|l|l|c|c|}
\hline \multicolumn{2}{|c|}{} & \multicolumn{2}{c|}{ Level of absolute poverty } \\
\cline { 3 - 4 } \multicolumn{2}{|c|}{} & Poor & Non-poor \\
\hline \multirow{2}{*}{$\begin{array}{l}\text { Women } 18 \text { to } 35 \text { years } \\
\text { in this village are highly } \\
\text { likely to be sexually abused }\end{array}$} & Disagree & $27(8.6)$ & $0(0)$ \\
\cline { 2 - 4 } & Neutral & $71(22.5)$ & $0(0)$ \\
\cline { 2 - 4 } & Agree & $217(68.9)$ & $33(64.7)$ \\
\cline { 2 - 4 } & Strongly Agree & $0(0)$ & $18(35.3)$ \\
\hline \multicolumn{2}{|l|}{ Total } & $\mathbf{3 1 5}$ & $\mathbf{5 1}$ \\
\hline
\end{tabular}


Table 7 shows the responses provided during the research with views sought from the respondents on the likelihood of women 18 to 35 years of age in the respective villages being sexually abused. The findings show that among the respondents living below the absolute poverty line 8.6 percent disagreed, 22.5 provided a neutral view and 68.9 percent agreed. Of the respondents living above the absolute poverty line 35.3 percent strongly agreed and 64.7 agreed that women 18 to 35 years of age in the respective villages were highly likely to be sexually abused.

Table 8: Girls 12-17 Years Get Pregnant and Absolute Poverty Line

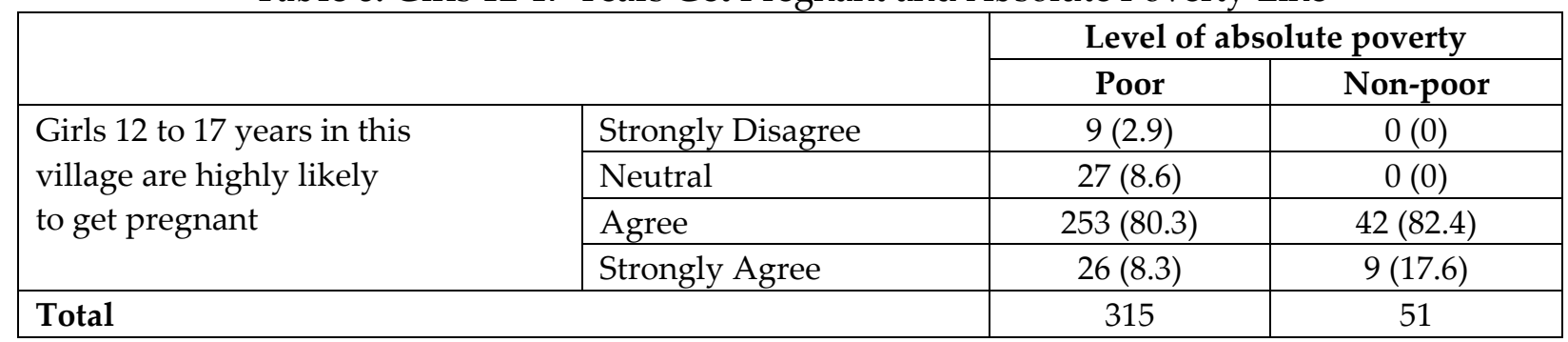

The research findings on Table 8 show that 2.9 percent of the respondents living below the absolute poverty line strongly disagreed, 8.6 percent were neutral on the subject, 80.3 percent agreed while 8.3 percent strongly agreed that girls between 12 and 17 years of age from the respective villages are highly likely to get pregnant. On the other hand, respondents living above the absolute poverty line 82.4 percent agreed and 17.6 percent strongly agreed that girls 12 to 17 years of age from the respective villages are highly likely to get pregnant.

Table 9: Girls 12 to 17 Blamed for Getting Pregnant and Absolute Poverty Line

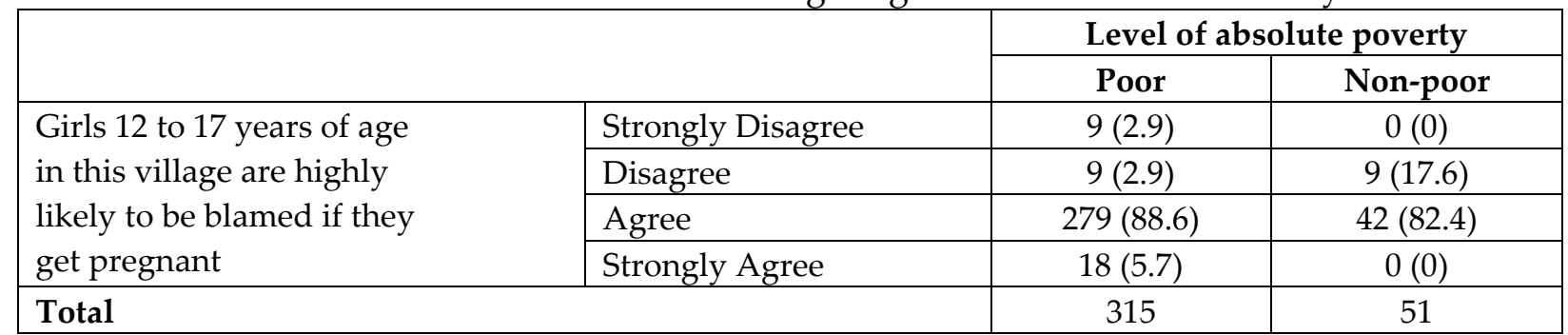

The research findings on Table 9 show responses from respondents living below the absolute poverty line and those living above it on girls 12 to 17 years of age in the respective villages highly likely to be blamed if they get pregnant. Among respondents living below the absolute poverty line 2.9 percent strongly disagreed, 2.9 percent disagreed 88.6 percent agreed and 5.7 percent strongly agreed that girls aged between 12 and 17 years of age are highly likely to be blamed if they get pregnant. As for the respondents living above the absolute poverty line, 17.6 percent disagreed and 82.4 percent agreed that girls 12 to 17 years of age are highly likely to be blamed if they get pregnant. 
Table 10: Girls below 18 years married and absolute poverty line

\begin{tabular}{|l|l|c|c|}
\hline \multicolumn{2}{|c|}{} & \multicolumn{2}{c|}{ Level of absolute poverty } \\
\cline { 3 - 4 } \multicolumn{2}{|c|}{} & Poor & Non-poor \\
\hline \multirow{2}{*}{$\begin{array}{l}\text { Girls in this village are highly } \\
\text { likely to get married before } \\
\text { attaining 18 years }\end{array}$} & Neutral & $81(25.7)$ & 0 \\
\cline { 2 - 4 } & Agree & $225(71.4)$ & $42(82.4)$ \\
\cline { 2 - 4 } & Strongly Agree & $9(2.9)$ & $9(17.6)$ \\
\hline \multicolumn{2}{|l|}{} & 315 & 51 \\
\hline
\end{tabular}

Table 11 shows the responses to the research findings on girls in the respective villages being highly likely to get married before attaining 18 years among respondents living below and above the absolute poverty line of $\$ 1.90$. Among the respondents living below the absolute poverty line 25.7 percent were neutral, 71.4 percent agreed and 2.9 percent strongly agreed. Among the respondents living above the absolute poverty line, 82.4 percent agreed and 17.6 strongly agreed that girls in the respective villages are highly likely to get married before attaining 18 years of age.

\section{Conclusions of the Study}

The researcher makes informed conclusions on the objectives from the research findings drawn from Madogo Ward. The conclusions will be provided in the order of the stipulated objectives of the study.

\subsection{Gender-based Violence}

The findings of the research from Madogo Ward confirm that women and girls are at a very high risk of gender-based violence in all the villages. Gender-based violence predisposes girls below 18 years and women to child marriage, female genital mutilation, sexual abuse, unwanted pregnancy, risk of contracting sexually transmitted diseases such as HIV/AIDS, and even death. This affects women in that they could get depressed, traumatized, drop out of school and even get into negative coping behaviors such as drug and substance abuse, prostitution, crime, and even suicide. Gender-based violence pushes women into poverty as they are not able to participate in the economy.

\section{Recommendations}

The researcher provides a host of recommendations from the study objectives to key stakeholders of gender and poverty organizations and departments. The recommendations are based on the inferences drawn from the research conclusions.

Government departments should also ensure that women are protected from gender-based violence by ensuring that they have access to reliable reporting channels, reproductive health education, enhanced community-based child protection mechanisms, and persecution of those found guilty of committing physical, emotional, and sexual violence against women and girls. The Ministry of Health should also ensure that women and girls that seek services in the hospital can get relevant information on 
reproductive health, provide medical services and avail medication for those visiting hospitals.

Religious organizations and community leaders should ensure that they condemn violence against women and girls and promote their empowerment instead. Development agencies and private institutions such as financial institutions should establish programs that will empower women to speak against violence facing women and girls and provide financial support to girls to complete school and economic empowerment of women.

\section{Conflict of Interest Statement}

The authors declare no conflicts of interests.

\section{About the Authors}

Kevin Nderitu Kaguthi is a postgraduate student in the Department of Social and Development studies at Mount Kenya University, Kenya.

Kennedy Matundu is a Professor in the department of social and Development studies in Mount Kenya University, Kenya.

\section{References}

Alessio, J. (2016). Social Problems and Inequality: social responsibility through progressive sociology. Routledge.

Austrian, K., Pinchoff, J., Tidwell, J. B., White, C., Abuya, T., Kangwana, B., Ochako, R., Wanyungu, J., Muluve, E., Mbushi, F., Mwanga, D., Nzioki, M., \& Ngo, T. D. (2020). COVID-19 Related Knowledge, Attitudes, Practices and Needs of Households in Informal Settlements in Nairobi, Kenya. SSRN Electronic Journal, April, 1-21. https://doi.org/10.2139/ssrn.3576785

Barasa, S. F., Wamue-ngare, G., \& Wanjama, L. (2013). Experience of school-related gender-based violence by pupils and the culture of silence: A case of primary Schools in Kasarani District, Nairobi County, Kenya. International Journal of Education and Research, 1(3), 1-20.

Creswell, J. W., \& Creswell, D. J. (2018). Research Design: Qualitative, Quantitative, and Mixed Methods Approaches. SAGE Publications.

Kamau, John, G., Wamukuru, David, K., Murithii, W., \& Maina, K. (2019). Research methods, data analysis and defenses; building competencies in education and social sciences research. Education and Social Sciences Research Association of Kenya.

Kenya National Bureau of Statistics, . (2019). 2019 Kenya Population and Housing Census Volume 1: Population by County and Sub-County. In 2019 Kenya Population and Housing Census: Vol. I (Issue November). https://www.knbs.or.ke/?wpdmpro=2019kenya-population-and-housing-census-volume-i-population-by-county-and-subcounty 
Ministry of Finance and UNICEF Ethiopia. (2019). National Situation Analysis of Children and Women in Ethiopia.

Misati, J. A., \& Mwenzwa, E. M. (2018). Kenya's Social Development Proposals and Challenges: Review of Kenya Vision 2030 First Medium-Term Plan , 2008-2012. American International Journal of Contemporary Research, 4(October).

Rabiu, A. (2018). Poverty among Women of Zangbalun in Kumbungu District of the Northern Region. In University of Ghana (Issue 10552661). University of Ghana.

Rahi, S. (2017). Research Design and Methods: A Systematic Review of Research Paradigms, Sampling Issues and Instruments Development. International Journal of Economics E Management Sciences, 06(02). https://doi.org/10.4172/2162-6359.1000403

Riumallo-Herl, C., Canning, D., \& Salomon, J. A. (2018). Measuring health and economic wellbeing in the Sustainable Development Goals era: development of a poverty-free life expectancy metric and estimates for 90 countries. The Lancet Global Health, 6(8), e843-e858. https://doi.org/10.1016/S2214-109X(18)30277-8

UNDP. (2018). Human Development Indices and Indicators.

World Bank. (2015). 2015 World Development Report.

World Data Lab (2020). No Title. World Poverty Clock. https://worldpoverty.io/map. 
Author(s) will retain the copyright of their published articles agreeing that a Creative Commons Attribution 4.0 International License (CC BY 4.0) terms will be applied to their work. Under the terms of this license, no permission is required from the author(s) or publisher for members of the community to copy, distribute, transmit or adapt the article content, providing a proper, prominent and unambiguous attribution to the authors in a manner that makes clear that the materials are being reused under permission of a Creative Commons License. Views, opinions and conclusions expressed in this research article are views, opinions and conclusions of the author(s). Open Access Publishing Group and European Journal of Education Studies shall not be responsible or answerable for any loss, damage or liability caused in relation to/arising out of conflicts of interest, copyright violations and inappropriate or inaccurate use of any kind content related or integrated into the research work. All the published works are meeting the Open Access Publishing requirements and can be freely accessed, shared, modified, distributed and used in educational, commercial and non-commercial purposes under a Creative Commons Attribution 4.0 International License (CC BY 4.0). 